\title{
Time Pressure, Satisfaction with Leisure, and Health Among Australian Women
}

\author{
Peter R. Brown, University of Newcastle \\ Wendy J. Brown, University of Queensland \\ Jennifer R. Powers, University of Newcastle
}

\begin{abstract}
Expectations associated with the multiple roles adopted by women over the life-course have contributed to feelings of time pressure and stress for many women. There is also a growing body of evidence that leisure participation contributes to individual health and well-being and may serve to moderate levels of stress. Explorations of associations between feelings of time pressure, satisfaction levels with the time spent in active/ passive leisure, and measures of physical and mental health, may provide insights into the role of leisure in promoting good health and moderating stress levels associated with increased time pressure for Australian women. Data from the baseline survey of the Women's Health Australia project are used to explore such associations in the lives of 41,000 Australian women aged 18-23, 45-50 and 70-75 in 1996. While being rushed/pressured/busy seems to impact adversely on health, the effects seem to be attenuated in women who are happy with the amount of leisure time available to them.
\end{abstract}

\section{Introduction}

While aggregate levels of free time may be rising in some Western countries, it has been reported that increasing numbers of people are experiencing time pressure and stress. Researchers have shown that perceptions of time pressure are unevenly distributed across different life cycle, employment and occupational groups, are strongly related to marital status and the presence and number of children, and tend to be reported more by women than men (Coverman, 1989; Hochschild, 1989; Schor, 1991; Robinson and Godbey, 1997; Bittman, 1998; Brown and Brown, 1999). There is also a growing body of evidence that leisure participation contributes to individual health and wellbeing and may serve to moderate levels of stress (Coleman and Iso-Ahola, 1993; Caltibiano, 1995; Iso-Ahola and Park, 1996; Brown, Ball and Powers, 1998; Zuzanek and Mannell, 1998).

As more women enter the labour force in Australia and other Western countries, there has been some speculation that women's increased involvement in paid employment would enhance their leisure experiences and quality of life 
(Deem, 1986; Green, Hebron and Woodward, 1990; Harrington and Dawson, 1995; Kay, 1996; Bryson and Warner-Smith, 1998). These and other studies have postulated that increased access to resources (both financial and social), a clearer separation between work and non-work time, and increased legitimacy of the claim to leisure arising from paid employment, would result in leisure 'gains' for women (Henderson, Bialeschki, Shaw and Freysinger, 1996). However, as we enter the twenty-first century, the basis for these expectations appears highly questionable. In their analysis of labour market trends and participation rates in the Australian labour force (see Australian Bureau of Statistics, 1995a), Brown and Rowe, (1998) highlight a growing diversity among women (and men) who may be divided, on the basis of hours in paid employment, into the 'leisure time rich' and 'leisure time poor'. Moreover, increased participation in the labour market, in combination with domestic and caring responsibilities, have increased a sense of 'time poverty' for many women. Those women who are in the child-rearing stage of their lives, in a couplerelationship and in full-time employment have, according to national time-use data, by far the least amount of leisure time of all Australians (ABS, 1995b; Bittman, 1998).

According to the most recent national survey into How Australians Use Their Time (ABS, 1998), women also report the highest levels of time pressure. In dual career families, $70 \%$ of women who are employed full-time and have dependent children (aged 0-14 years) report 'always/often' feeling rushed for time, compared with $56 \%$ of males and $51 \%$ of women who are not employed. Where there are no dependent children, $52 \%$ of women in full-time employment report feeling rushed, compared with $44 \%$ of men and $14 \%$ of women who are not employed (ABS, 1999a). Given these trends, it is not surprising that 'no time' is by far the most commonly reported barrier to leisure participation (see, for example: Shaw, 1985; Searle and Jackson, 1985; Horna, 1989; Shaw, Bonen and McCabe, 1991; Kay, 1998). No time is also the main reason Australians give for 'dropping out' of sport (ABS, 1999b) and failing to 'drop into' cultural activities (Australia Council, 1995). Despite perceptions of time scarcity and time pressure, data from the 1997 Australian time-use survey (which included a random sample of 8600 people aged 15 years and over) show that Australians spend an average of 326 minutes a day on free time activities, with men (328 minutes) allocating 24 minutes more than women (304 minutes). Although these aggregate data provide useful information on the general availability of leisure time, they do not allow exploration of valuations in patterns of time-use among women with labour, family and household commitments.

For many women, it is difficult to separate different time expenditures which, in combination, could contribute to role overload and a sense of time pressure (Robinson and Godbey, 1998; Peters and Raaijmakers, 1998; Bittman, 
1999). Some researchers argue that it is not the fulfilment of several roles simultaneously (role overload) which causes stress, but rather the extent to which the pressures of one role (e.g. as a mother) may be incompatible with pressures associated within another role (e.g. as a professional). Women's experience of 'role conflict', it has been argued, may contribute to a heightened sense of time pressure and stress due to perceived dissatisfaction with the balance of work and leisure, and their frustration with divisions of domestic labour, which are perceived as inequitable (Coverman, 1989; Kay, 1998).

Whether or not these interactions between time pressure, perceived lack of leisure and stress impact negatively on women's health, is unclear. However, data from the Canadian national population health and national time-use surveys suggest there may be important links between stress, leisure participation and health at different stages of the lifecycle (Iwasaki and Smale, 1998; Zuzanek and Mannell, 1998). In Australia, the Australian Longitudinal Study on Women's Health, now known as the Women's Health Australia (WHA) project, provides another opportunity to explore the effect of these issues on women's health and well-being.

The WHA study involves three national cohorts of women who are broadly representative of three different generations. The overall aim of the project is to determine the biological, psychological, social and environmental issues which cause ill health in Australian women. In this paper we explore the characteristics of WHA participants who feel time pressured, and the inter-relationships between time pressure, satisfaction with leisure, and physical and mental health. In view of the current policy debates about the benefits of women's increased participation in the paid work force, we aim in this study to determine:

i) the proportion of women in each of three age groups who report feeling time pressured;

ii) whether there are any deleterious effects on health for women who are constantly time pressured; and, if so,

iii) whether satisfaction with the time spent in active and passive leisure can ameliorate the health effects of being rushed and time pressured.

\section{Methods}

\section{Study sample}

More than 41,000 women aged 18-23 ('young'), 45-50 ('mid') and 70-75 years ('older'), responded to the baseline survey of the Australian Longitudinal Study of Women's Health in 1996. Participants were randomly selected from women registered on the national Medicare database, which includes almost all people who are resident in Australia, including migrants and refugees. Women living 
in rural and remote areas were over-sampled. Allowing for inaccuracies in the Medicare database, it is estimated that $41-42 \%, 53-56 \%$, and $37-40 \%$ of the selected young, mid and older women, respectively, chose to participate in the study (Brown, Dobson, Bryson and Byles, 1999). The usual methods of encouraging participation, such as telephone calls, were not possible because the names of the selected women were unknown to researchers. However, response rates compare favourably with previous studies which have depended solely on postal recruitment, and the respondents were broadly representative of the national population of women in the same age groups, with some overrepresentation of women with certificates, diplomas or university degrees and under-representation of immigrant women (Brown et al., 1999).

\section{Questionnaire and measures}

The baseline surveys included questions on a wide range of issues designed to explore social, psychological and biological aspects of women's lives. Only those questions hypothesised to be related to health, time-use and leisure were included in the analyses for this paper.

Physical and mental health were assessed using the MOS Short Form Health Survey (SF36) (Ware, Kosinski and Keller, 1994). Summary physical and mental health component scores were calculated and standardised so that a score below 50 indicates worse, and above 50 indicates better health than the mean of the population (Mishra and Schofield, 1998).

Time pressure was assessed using a single question: 'How often do you feel rushed/pressured/too busy?'. Response options were 'every day', 'a few times a week', 'about once a week', 'about once a month' and 'never' (Statistics Canada, 1987). Responses were dichotomised to 'frequently rushed' (every day/a few times a week) and 'less rushed' (once a week/once a month/never).

Women were also asked: 'How happy are you with the amount of time you spend in ACTIVE (e.g. sport, art, drama, music) and PASSIVE leisure (e.g. reading, TV, writing letters)?'. Response options were 'Happy the way it is', 'Would like to do more', 'Would like to do less' and 'Not applicable/Don't do this)' (ABS, 1993).

The women also answered questions about demographic and social characteristics. Responses to questions on marital status (married, de facto), employment status (full-time or part-time paid work, work in a family business, student, voluntary work), hours worked each week (35 or more), having children living at home (yes/no), caring (yes/no), and dissatisfaction with share of domestic/caring duties (yes/no), were also used to assess the proportion of women in each cohort who were likely to be 'time pressured.' 


\section{Statistical analysis}

To correct for over-sampling of women from rural and remote areas, all responses were weighted for area so that the study population was representative of the Australian population for women in these age groups. After applying these weights, socio-demographic and time pressure characteristics of the women were compared for the three age groups.

Women who responded 'Would like to do less' or 'Not applicable /Don't do this)' to the questions about satisfaction with the amount of time available for leisure were excluded from the analyses about satisfaction with leisure time. Fewer than $0.5 \%$ of women in all cohorts ( 70 young, 42 mid-age and 16 older women) said they would like less time for active leisure. Overall, 3\% (1003 young, 251 mid-age and 113 older) of the women said they would like less time for passive leisure. Almost two-thirds of the young women and half the mid-age women who responded in this way were not in paid work. Women who answered 'not applicable' to the active leisure question were also excluded (991 young, 2581 mid-age and 5103 older) from the final stage of the analysis, because $65 \%$ of the young, $82 \%$ of the mid-age and $89 \%$ of the older women who responded in this way also answered 'never' to the question: 'In a normal week, how many times do you engage in vigorous exercise lasting 20 minutes or more?'. It would appear therefore that many of these women interpreted this question to mean 'do you participate in active leisure?'

Means and 95\% confidence intervals (CI) were calculated for physical and mental health component scores, for time pressure ('frequently rushed', 'less rushed') and for the leisure categories of 'happy' and 'like more' using the means procedure of SAS (SAS, 1989). Although no definitive guidelines exist as yet, normative data from The 1995 National Health Survey (ABS, 1997) show that the presence of one serious physical condition (e.g. cancer, heart disease, diabetes, hypertension, asthma, arthritis) results in decreases of physical and mental health component scores of 3.3 and 2.1 respectively.

\section{Results}

The demographic characteristics of the women in each cohort are shown in Table 1. Compared with the other two groups, a greater proportion of the younger women were Australian born and a smaller proportion of the older women had higher educational qualifications. In terms of possible causes of time pressure, the majority of the mid-age women had a partner, and most of the young and mid-age women were working or studying, with many working 35 hours or more each week. Two-thirds of the mid-age women compared with only one in ten of the young women had children living at home. 
Table 1. Socio-demographic characteristics and factors related to time pressure for women in three cohorts ${ }^{\dagger}$

\begin{tabular}{|c|c|c|c|c|}
\hline & & $\begin{array}{c}\text { Young } \\
\mathrm{N}=14779\end{array}$ & $\begin{array}{c}\text { Mid } \\
\mathrm{N}=14100\end{array}$ & $\begin{array}{c}\text { Older } \\
\mathrm{N}=12939\end{array}$ \\
\hline & & $\%$ & $\%$ & $\%$ \\
\hline \multirow[t]{5}{*}{ Country of birth } & Australia & 90 & 70 & 73 \\
\hline & Other English speaking & 4 & 16 & 14 \\
\hline & Europe & 1 & 9 & 10 \\
\hline & Asia & 4 & 4 & 2 \\
\hline & Other & 1 & 2 & 1 \\
\hline \multirow{4}{*}{$\begin{array}{l}\text { Highest } \\
\text { qualification } \\
\text { completed }\end{array}$} & No formal & 3 & 17 & 34 \\
\hline & School & 67 & 47 & 51 \\
\hline & Trade/certificate/diploma & 18 & 20 & 12 \\
\hline & University & 12 & 17 & 4 \\
\hline \multirow[t]{5}{*}{ Marital status } & Married & 8 & 75 & 55 \\
\hline & Defacto & 12 & 6 & 1 \\
\hline & Separated/ divorced & 1 & 13 & 6 \\
\hline & Widowed & 0 & 2 & 35 \\
\hline & Single & 79 & 4 & 3 \\
\hline \multirow{4}{*}{$\begin{array}{l}\text { Employment } \\
\text { status* }\end{array}$} & Full time & 32 & 38 & - \\
\hline & Part time & 20 & 32 & - \\
\hline & $\begin{array}{l}\text { Family business unpaid, } \\
\text { vol., studying }\end{array}$ & 34 & 8 & - \\
\hline & Retired, unemployed, ill & 14 & 23 & - \\
\hline \multirow{4}{*}{$\begin{array}{l}\text { Hours in paid } \\
\text { work per week* }\end{array}$} & none & 48 & 30 & - \\
\hline & $1-34$ & 19 & 33 & - \\
\hline & $35-40$ & 21 & 22 & - \\
\hline & 41 or more & 12 & 19 & - \\
\hline \multirow{4}{*}{$\begin{array}{l}\text { Number of } \\
\text { children } \\
\text { (living at home* } \\
\text { for mid) }\end{array}$} & None & 92 & 34 & - \\
\hline & One & 6 & 26 & - \\
\hline & Two & 2 & 27 & - \\
\hline & Three or more & 0 & 13 & - \\
\hline \multicolumn{2}{|c|}{$\begin{array}{l}\text { Regularly provide care due to long-term } \\
\text { illness, disability or frailty }\end{array}$} & 8 & 20 & 17 \\
\hline \multirow{4}{*}{$\begin{array}{l}\text { Unhappy with } \\
\text { share of the } \\
\text { following tasks }\end{array}$} & Domestic work & 26 & 43 & 9 \\
\hline & Child care & 3 & 4 & - \\
\hline & Caring for another adult & 2 & 8 & 3 \\
\hline & Other household work & 13 & 35 & 12 \\
\hline
\end{tabular}

$\overline{~ W e i g h t e d ~ t o ~ a l l o w ~ f o r ~ o v e r-s a m p l i n g ~ o f ~ w o m e n ~ l i v i n g ~ i n ~ r u r a l ~ a n d ~ r e m o t e ~ a r e a s . ~}$

* Not asked in older survey. Sample numbers vary due to missing data. 
Approximately $20 \%$ of the mid-age and older women regularly provided care for someone because of long-term illness, disability or frailty. More than half the mid-age women, and a third of young women, but fewer than one in five of the older women, were unhappy with their share of domestic and caring tasks (composite data not shown).

Responses to the time pressure questions are shown in Table 2. Almost $60 \%$ of the women in the mid-age group reported three or more 'time pressure' factors, whereas women in the other two age groups were more likely to report fewer than two of these factors. However, almost two-thirds of the young and mid-age women frequently felt rushed, compared with fewer than a quarter of the older women (see Table 3).

Table 2. Proportion of women who reported different numbers of 'time pressure' factors*, in three cohorts $^{\dagger}$

\begin{tabular}{lccc} 
Time impacts* & $\begin{array}{c}\text { Young } \\
\%\end{array}$ & $\begin{array}{c}\text { Mid } \\
\%\end{array}$ & $\begin{array}{c}\text { Older } \\
\%\end{array}$ \\
\hline None & 13 & 2 & 32 \\
One & 49 & 13 & 49 \\
Two & 28 & 27 & 15 \\
Three & 9 & 35 & 3 \\
Four & 1 & 20 & 0 \\
Five & 0 & 3 & 0 \\
\hline $\mathrm{N}$ & 14,208 & 13,510 & 12,259 \\
\hline
\end{tabular}

$\dagger$ Weighted to allow for over-sampling of women living in rural and remote areas.

* Having a partner, in the workforce or studying, working 35 hours or more each week in paid work, children living at home, caring for someone, unhappy with share of domestic/caring tasks

Table 3. Responses to: 'How often do you feel rushed/pressured/busy?' ${ }^{\dagger}$

\begin{tabular}{lccc}
\hline & Young & Mid & Older \\
How often feel rushed & $\%$ & $\%$ & $\%$ \\
\hline Every day & 18 & 23 & 4 \\
A few times a week & 44 & 41 & 19 \\
About once a week & 21 & 17 & 20 \\
About once a month & 11 & 11 & 19 \\
Never & 5 & 8 & 38 \\
\hline $\mathrm{N}$ & 13,864 & 13,856 & 12,654 \\
\hline$\quad$ Weighted to allow for over-sampling of women living in rural and remote areas.
\end{tabular}

Mean physical and mental health component scores were consistently lower for women who frequently felt rushed than in those who were less rushed, in all three age groups (data not shown). Mean differences between these groups 
for physical health component scores were relatively small ${ }^{1}$, however the mean differences in mental health component scores were more marked and likely to be clinically significant ${ }^{2}$.

In general, women who reported that they would like more time for either active or passive leisure were more likely to frequently feel rushed (see Figure 1). Mean physical health component scores were only slightly higher in women who were happy with their leisure time, compared with those who would like more time available for active $e^{3}$ or passive leisure. However, mean mental health component scores were significantly higher for women who were happy with time available for both active $e^{5}$ and passive ${ }^{6}$ leisure.

When both 'feeling rushed' and 'satisfaction with time available for leisure' were taken into account, the lowest PCS and MCS scores were observed in women who were 'frequently rushed' and who would like more time for leisure (see Table 4).'Frequently rushed' women in all three cohorts, who were happy with the amount of time available for both active and passive leisure, had significantly higher MCS scores than those who were not happy with their leisure time. In general, the highest PCS and MCS scores were seen in women who were less rushed, and who were happy with their leisure time. The greatest differences across categories were seen for active leisure and mental health. Time expenditures associated with various combinations of these roles clearly peak for women at certain stages of the lifecycle (e.g. in mid-age) and diminish in later life, as illustrated by the lower level of time pressure experienced by women in the older cohort in this study.

${ }^{1}$ young 1.8 (CI 50.9; 51.4-49.2; 49.7); mid-age 0.6 (CI 50.3; 50.8- 49.6; 50.1); older 1.5 (CI 50.2; 50.6- 48.5; 49.3)

${ }^{2}$ young 4.4 (CI 52.5; 53 - 48.2; 48.7); mid-age 4.5 (CI 52.8; 53.3 - 48.2; 48.7); older 5.2 (CI 51.2; $51.6-45.8 ; 46.6)$

${ }^{3}$ young: 1.2 (CI 51.1; $\left.51.7-50.5 ; 50.4\right)$; mid-age: 1.0 (CI 51.2; $51.7-50.2 ; 50.6$ ); older: 2.5 (CI $51.9 ; 52.4-49.1 ; 50.1)$

${ }^{4}$ young: 0.8 (CI 50.4; 50.8 - 49.6; 50.1); mid-age: 0 (CI 50.0; $50.4-49.9 ; 50.4$ ); older: 1.3 (CI $50.1 ; 50.5-48.6 ; 49.5$ )

${ }^{5}$ mean differences: young 3.6 (CI 52.6; 53.3 - 49.1; 49.5); mid-age 3.5 (CI 52.5; 53.1 - 49.1; 49.5); older 3.6 (CI 51.9; $52.4-48 ; 49$ )

${ }^{6}$ mean differences: young 3.0 (CI 51.4; 51.9 - 48.4; 48.9); mid-age 2.6 (CI 51.3; 51.8 - 48.6; 49.1); older 3.0 (CI 50.8; 51.2 - 47.5; 48.5) 
Figure 1. Women in each 'rush category' who said they would like more time for active or passive leisure (weighted for area) [for $\mathbf{N}$ see Table 4]



\section{Discussion}

The self-reported levels of time pressure experienced by women in this study indicate that half of those sampled feel 'frequently rushed', and that perceptions of time pressure vary between the three age cohorts. Almost two thirds of the mid-age and young women, respectively, feel 'rushed/pressured/busy' more than a few times a week, compared with fewer than one quarter of the older women. Similar levels of time pressure for women have been reported in national timeuse surveys conducted in Australia (ABS, 1999a) and North America (Robinson and Godbey, 1997), where those women with least 'free' time (e.g. middle-aged mothers of pre-school children who are in full-time employment) report the highest levels of feeling time pressured (ABS, 1999a; Bittman, 1998). Such data provide empirical support for those researchers who argue that the volume and often fragmentary nature of activities associated with women's multiple roles (e.g. as mother, housekeeper, carer and paid employee) contribute to a sense of 'role overload' and 'role conflict', as well as a heightened perception of time compression (Coverman, 1989; Hochschild, 1989; Schor, 1991; Henderson et al, 1996; Kay, 1998; Peters and Raaijmakers, 1998; Zuzanek, Beckers and Peters, 1998; Bittman and Wajcman, 1999). 


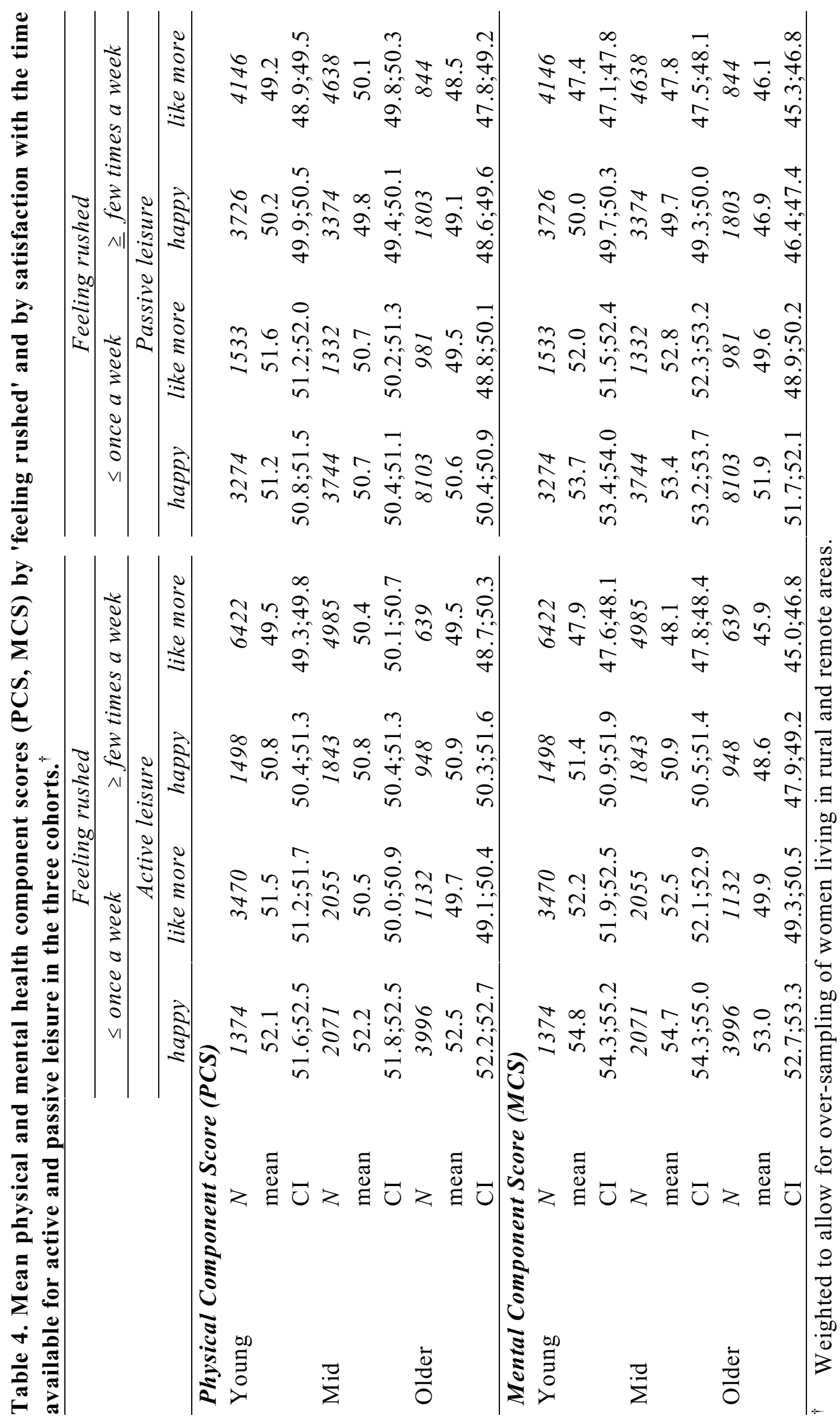


While relative levels of 'role overload' may explain differences in time pressure experienced by women in the mid-age and older cohorts, they fail to adequately explain the high levels of time pressure reported by the younger women. While roles associated with employment, marital status and presence of children can affect 18-23 year old women, $90 \%$ of this group reported two or less of the 'time pressure' factors described here, compared with $42 \%$ of women in the mid-aged cohort. It is clear therefore, that the factors which explain time pressure for their mothers' generation do not adequately capture the causes of time pressure for young women.

One explanation might be that, for women in the younger cohort, the perceived intensity with which different pressures on time are experienced, may be more important than the number of time pressure factors in explaining different levels of reported time pressure. For example, many of the young women in this study are 'full-time' students, but also report high rates of participation in the paid workforce. It is also possible that the high level of time pressure reported by the young women could be due to generational differences in the way time is experienced. A number of writers have attributed increasing levels of time pressure (in Western society) to technology and a 'speed up in the pace of life' (see, for example, Rifkin, 1987; Glieck, 1999). It may well be that children of the 'computer revolution' - women in the young cohort - have developed what Schor (1991:24) has called an 'accelerated sense of time'. Advanced technologies and increased prosperity (in most industrialised countries) have also led to a culture of rising expectations which may, perhaps, be felt more keenly by a generation that has not experienced the Great Depression or the uncertainties surrounding the Cold War. Since time is finite, one response to perceived time famine is to engage in 'time deepening' behaviours, where individuals try to pack as many experiences as possible into a 24-hour day. Compared with their parents and grand-parents, the young women may be simply doing more things and doing them more quickly, thereby increasing their sense of time pressure.

To date, there has been surprisingly little attention paid to generational differences in time-use and attitudes towards time. For women who were born in the 1970s - the so-called 'options' generation (McKay, 1997) - the pursuit of multiple options, underpinned by a culture of rising expectations and an accelerated sense of time, may contribute to relatively high levels of reported time pressure. While the increased pace of life may also affect women in the other two cohorts, it is likely that relative levels of reported time pressure experienced by mid-age and older women may be more closely related to time expenditures associated with women's multiple roles that vary over the life cycle (Zuzanek and Mannell, 1998). Whatever the reasons, if women do feel time pressured what are the implications of this for their physical and mental health? 
Data from this study indicate that women who are rushed a few times a week or every day have significantly worse mental health than women who are not rushed/pressured/busy. Mean physical health component scores were also consistently lower for women who frequently felt rushed than for those who were less rushed, in all three age groups. These findings lend support to the work of several researchers who have speculated about the detrimental effects on women's health caused by the time and labour demands associated with multiple roles and women's increasing presence in the paid labour market (see, for example, Coverman, 1989; Schor, 1991; Facione, 1994). The data are also consistent with the views of researchers, such as Robinson and Godbey (1998: 477), who have argued that stress is most commonly experienced in relation to 'multiple role pressures and expanding opportunities that are felt stronger because of a lack of time' (see also Zuzanek and Mannell, 1998).

Although some researchers have reported that multiple role involvements (for example, as wife, mother and employee) may actually enhance psychological health and well being (see, for example, Verbrugge, 1983; Barnett and Baruch, 1985; Harrington and Dawson, 1995), the data in this study do not support these conclusions. For many women, it would appear that the 'juggling act' between job and family contributes to a sense of 'time poverty', overwork and stress with detrimental effects on both mental and physical health.

Notwithstanding this, from the results presented here, it would appear that, for those women who are 'busy', satisfaction with time spent in leisure may help to moderate feelings of time pressure, and have beneficial health effects. This is especially true for the mental health benefits of active leisure in all three age groups. There are, however, also some health benefits of satisfaction with time spent in passive leisure, a finding which suggests that 'time out' for recuperative leisure, such as reading or watching television, may also be important for women's mental health.

These findings lend support to a number of small-scale studies that have demonstrated a significant relationship between positive attitudes to leisure and psychological health (Cassidy, 1996; Pearson, 1998). While it is not clear if those who feel healthier are more likely to feel positive about the amount of time devoted to leisure, or whether those who have positive attitudes towards leisure (and presumably participate in leisure) are likely to feel healthier and happier, there are clear associations between leisure and health. The data also support the findings of several population-based empirical studies on the relationship between leisure, stress and health that have reported 'buffering effects' attributable to leisure participation (Iwasaki and Smale, 1998; Zuzanek and Mannell, 1998). For example, Zuzanek and Mannell (1998) argue that the effects of role overload and time pressure on stress and mental health may be offset by emotional stability 
associated with other life domains, such as a stable marriage, good health, financial security and leisure.

One limitation of this study is the cross-sectional nature of the data, as no causal relationships can be inferred. Another limitation might be the use of 'satisfaction with leisure time' rather than estimates of the amount of time spent in leisure activities. The findings suggest a need to further refine and integrate measures of time, time pressure, stress and health. In forthcoming WHA surveys we have asked women to report on the actual time spent in a range of activities, and when these data are available we will be able to explore further the attenuating effects of leisure on the relationship between time pressure and health.

In conclusion, the data presented here suggest that being rushed/pressured/ busy seems to impact on health (particularly mental health) and that the effects are attenuated in women who are happy with the leisure time available to them. It is unlikely that leisure in itself will be able to 'correct' the current 'role overload' which is experienced by many women, but for those women who have the necessary control over their time to make time for active and/or passive leisure, there may be health benefits in the longer term. Future surveys in this longitudinal study will allow further exploration of this hypothesis.

\section{Acknowledgements}

The research assistance of Vibeke Hansen (Department of Leisure and Tourism Studies, University of Newcastle) in gathering information for this study is gratefully acknowledged. This study is part of the Australian Longitudinal Study on Women's Health which commenced in 1995 with funding from the Australian Commonwealth government. More information about the project can be obtained from the website: www.fec.newcastle.edu.au/wha.

\section{References}

ABS - see Australian Bureau of Statistics.

Australia Council (1995) The Arts: Some Australian Data. Redfern, NSW, Australia Council.

Australian Bureau of Statistics (1993) Time Use Survey, Australia, 1992 Users Guide. Canberra, Australian Bureau of Statistics.

Australian Bureau of Statistics (1995a) The Australian Labour Market-1994. Canberra, Australian Bureau of Statistics.

Australian Bureau of Statistics (1995b) The Australian Women's Year Book, 1995. Canberra, Australian Bureau of Statistics.

Australian Bureau of Statistics (1997) National Health Survey Australia, 1995: SF-36

Population Norms. Canberra, Australian Bureau of Statistics. 
Australian Bureau of Statistics (1998) How Australians Use Their Time, (Cat. No. 4153.0). Canberra, Australian Bureau of Statistics.

Australian Bureau of Statistics (1999a) Australian Social Trends, 1999, (Cat. No. 4102.0). Canberra, Australian Bureau of Statistics.

Australian Bureau of Statistics (1999b) Participation in Sport and Physical Activities 1988-99. Canberra, Australian Bureau of Statistics.

Barnett, R. and Baruch, G. (1985) Women's involvement in multiple roles and psychological distress. Journal of Personality and Social Psychology, 49, 135-145.

Bittman, M. (1998) The land of the lost long weekend? Trends in free time among working age Australians, 1974-1992. Society and Leisure, 21(2), 353-378.

Bittman, M.(1999) Social Participation and Family Welfare: The Money and Time Cost of Leisure. Sydney, Social Policy Research Centre, University of New South Wales.

Bittman, M. and Wajcman, J. (1999) The Rush Hour: The Quality of Leisure and Time and Gender Equity. Sydney, Social Policy Research Centre, the University of New South Wales.

Brown, P. and Brown, W. (1999) Work and leisure: does all work and no play make Jill unwell? World Leisure and Recreation, 41(1), 11-14.

Brown, P. and Rowe, D. (1998) The coming of a leisure society? Leisure time use in contemporary Australia. In Tourism, Leisure, Sport: Critical Perspectives, (edited by D. Rowe and G. Lawrence), Sydney, Hodder Headline, 89-99.

Brown, W., Ball, K., and Powers, J. (1998) Is life a party for young women? The ACHPER Healthy Lifestyles Journal, 45(3), 21-26.

Brown W.J., Dobson A. J., Bryson L. and Byles J. E. (1999) Women's Health Australia: on the progress of the main cohort studies. Journal of Women's Health, 8, 681-688.

Bryson, L. and Warner-Smith, P. (1998) Employment and women's health, Just Policy, 14(1), 3-14.

Caltabiano, M. (1995) Main and moderating health benefits of leisure. Society and Leisure, 18(1), 33-52.

Cassidy, T. (1996) All work and no play: a focus on leisure time as a means for promoting health. Counselling Psychology Quarterly, 9(1), 77-90.

Coleman, D. and Iso-Ahola, S. (1993) Leisure and health: the role of social support and self-determination. Journal of Leisure Research, 25(2), 111-128.

Coverman, S. (1989) Role overload, role conflict, and stress: Addressing consequences of multiple role demands. Social Forces, 67(4), 965-982.

Deem, R. (1986) All Work and No Play? The Sociology of Women and Leisure. Milton Keynes, Open University Press.

Facione, N. (1994) Role overload and health: the married mother in the waged labour force, Health Care for Women International, 15(1), 157-167.

Glieck, J. (1999) Faster.The Acceleration of Just About Everything, London, Little, Brown and Company.

Green, E., Hebron, S., and Woodward, D. (1990) Women's Leisure: What Leisure? London, Macmillan. 
Harrington, M. and Dawson, D. (1995) Who has it best? Women's labor force participation, perceptions of leisure, and constraints to enjoyment of leisure. Society and Leisure, 15(1), 203-222.

Henderson, K., Bialeschki, D., Shaw, S., and Freysinger, V. (1996) Both Gains and Gaps: Feminist Perspectives on Women's Leisure. State College, PA, Venture.

Hochschild, A. with Machung, A. (1989) The Second Shift. New York, Viking.

Horna, J.L. (1989) The leisure component of the parental role. Journal of Leisure Research, 21(2), 228-241.

Iso-Ahola, S. and Park, C. (1996) Leisure-related social support and self-determination as buffers of stress-illness. Journal of Leisure Research, 28 (3), 169-187.

Iwasaki, Y. and Smale, B. (1998) Longitudinal analyses of the relationships among life transitions, chronic health problems, leisure and psychological well-being. Leisure Sciences, 20(1), 25-52.

Kay, T. (1996) Women's work and women's worth: the leisure implications of women's changing employment patterns. Leisure Studies, 15(1), 49-64.

Kay, T. (1998) Having it all or doing it all? The construction of women's lifestyles in time-crunched households. Society and Leisure, 21(2), 435-454.

McKay, H. (1997) Generations, Sydney, Macmillan.

Mishra, G, and Schofield, M. (1998) Norms for the physical and mental component summary scores of the SF-36 for young, middle and older Australian women. Quality of Life Research, 7(2), 215-220.

Pearson, Q. (1998) Job satisfaction, leisure satisfaction, and psychological health. The Career Development Quarterly, 46(4), 416-426.

Peters, P. and S. Raaijmakers (1998) Time crunch and the perception of control over time from a gendered perspective: the Dutch case. Society and Leisure, 21 (2), 417-433.

Rifkin, J. (1987) Time Wars: The Primary Conflict in Human History. New York, Holt. Robinson, J. and Godbey, G. (1997) Time for Life: The Surprising Ways Americans Use Their Time. University Park, PA, Pennsylvania State University Press.

Robinson, J. and Godbey, G. (1998) Trend, gender, and status differences in American's perceived stress. Society and Leisure, 21(2), 473-488.

SAS Institute Inc.(1989) SAS/STAT Users Guide, Version 6, 4th Edition. Volume 1. Cary, NC, SAS Institute Inc.

Schor, J. (1991) The Overworked American: The Unexpected Decline of Leisure. New York, Basic Books.

Searle, M.S, and Jackson, E.L. (1985) Socio-economic variations in perceived barriers to recreation participation among would-be participants, Leisure Sciences, 7(2), 227 249.

Shaw, S. (1985) Gender and leisure: Inequality in the distribution of leisure time, Journal of Leisure Research, 17(4), 266-282.

Shaw, S.M., Bonen, A., and McCabe, J.F. (1991) Do more constraints mean less leisure? Examining the relationship between constraints and participation. Journal of Leisure Research, 23(4), 286-300.

Statistics Canada, Housing Family and Social Statistics Division (1987) General Social Survey Analysis Series. Ottawa, Canadian Government Publication Centre. 
Verbrugge, L. (1983) Multiple roles and physical health of women and men. Journal of Health and Social Behaviour, 24(1), 16-30.

Ware, J.E., Kosinski, M. and Keller, S.D. (1994) SF 36 Physical and Mental Health Summary Scales: A User's Manual. Boston, The Health Institute, New England Medical Centre.

Zuzanek, J. and Mannell, R. (1998) Life-cycle squeeze, time pressure, daily stress, and leisure participation: a Canadian perspective. Society and Leisure, 21(2), 513-544.

Zuzanek, J., Beckers, T., and Peters, P. (1998) The 'harried leisure class' revisited: Dutch and Canadian trends in the use of time from the 1970s to the 1990s. Leisure Studies, 17(1), 1-19. 